\title{
Possibilities of using lianas for greening automobile roads
}

\author{
Marina Radkevich ${ }^{1 *}$, Tojinur Pulatova ${ }^{2}$, Kamila Shipilova ${ }^{1}$, Oleg Pochuzhevsky ${ }^{3}$, \\ Abdusamin Gapirov ${ }^{2}$ and Murat Turakulov ${ }^{2}$ \\ ${ }^{1}$ Tashkent Institute of Irrigation and Agricultural Mechanization Engineers, Tashkent, Uzbekistan \\ ${ }^{2}$ Tashkent State Transport University, Tashkent, Uzbekistan \\ ${ }^{3}$ Krivoy Rog National University, Dnepropetrovsk, Ukraine
}

\begin{abstract}
The environmental problems of the road transport system in Tashkent are analyzed in the article. Particulate air pollution is one of the most serious problems. To reduce dust pollution in the air, it is proposed to create protective screens along highways from lianas. It was proposed to form screens from fragrant honeysuckle (Lonícera caprifólium) and ivy (Hedera helix), which are evergreen in the conditions of Tashkent. The study of the dust-absorbing capacity of the leaves of these plants showed that ivy leaves are the most dust-absorbing, capable of holding up to 1.64 $\mathrm{mg}$ of dust per $1 \mathrm{~cm}^{2}$ of the surface.
\end{abstract}

\section{Introduction}

During the years of independence, an intensive growth of motorization has been steadily observed in Uzbekistan. Following this, the road network is constantly changing and expanding. The development of the automobile and road complex, besides an undoubtedly positive impact on the country's economy, leads to negative consequences in the form of air and soil pollution with dust, gases, operating materials, and sound waves. Considering the level of motorization in large cities (in Tashkent, for example, there are 168 cars per 1000 inhabitants [1]), the problem of pollution becomes catastrophic and requires urgent action.

Road transport is not the least factor in the climate change process, as cars emit significant amounts of greenhouse gases (GHG), (various sources indicate the share of $\mathrm{CO}_{2}$ emissions from road transport from 13 to $27 \%$ of global emissions).

In 2004, transport contributed approximately $23 \%$ of total energy-related GHG emissions, with $\mathrm{CO}_{2}$ and $\mathrm{N}_{2} \mathrm{O}$ emissions of about 6.3-6.4 $\mathrm{GtCO}_{2}$-eq. $\mathrm{CO}_{2}$ emissions from the transport sector $\left(6.2 \mathrm{GtCO}_{2}\right.$-eq in 2004$)$ have increased by approximately $27 \%$ since 1990 and are fast growing in end-use sectors. Road transport now accounts for $74 \%$ of total transport $\mathrm{CO}_{2}$ emissions [2, 3].

Particulate air pollution presents a great danger during vehicle operations. Azarov et al. [4] indicate that during the vehicle operation, as a result of wear during the service life of the tire, the following average values of air pollution are emitted into the environment:

\footnotetext{
*Corresponding author: m.radkevich@tiiame.uz
} 
- from tires of passenger cars $1.4-1.9 \mathrm{~kg}$;

- from tires of light and heavy trucks $3.2-4.0 \mathrm{~kg}$ and $12.7-17.7 \mathrm{~kg}$, respectively.

The emission of particulate matter from tire tread wear in vehicles up to 3.5 tones is $0.051 \mathrm{~g} / \mathrm{km}$, which is approximately 5 times higher than the UNECE particulate matter emission standards for engines installed on these vehicles.

Improving the environmental performance of the road complex is consistent with sustainable development goals. The Resolution of the Cabinet of Ministers "On Measures to Implement the National Goals and Targets in the field of Sustainable Development for the Period until 2030" includes the task to ensure access to safe, affordable, and environmentally sustainable transport systems by 2030 [5]. First, the stability of transport systems must be ensured in large cities, such as the capital of Uzbekistan, Tashkent. While transport is not a distinct aspect of sustainable development, it is directly related to the Sustainable Cities and Human Settlements SDG. The concept of "stability of transport" has long been used in foreign scientific publications $[6,7,8]$. And the goals of ensuring the sustainability of transport for the target year 2030 include, in particular, such a task as reducing emissions of particulate matter by 55-99\% compared to 1990 level [8].

To solve this problem, various solutions are currently proposed: transition to alternative fuels, changing the operational characteristics of the road surface, and creating sanitary zones.

In Tashkent, some of these activities are also performed. In particular, compressed or liquefied gas is increasingly used as fuel in road transport. However, the pace of the transition to gas fuel is not too fast: to date, approximately $28 \%$ of the capital's vehicle fleet was switched to gas [6].

There is practically no control of particulate matter emissions in Uzbekistan, and scientific studies on the assessment and reduction of particulate matter emissions (PM10, PM5, PM2.5) are scarce.

It has long been known that greening can be effectively used to combat toxic emissions and noise pollution generated by transport $[9,10]$. In Uzbekistan, there is a departmental normative document MKN 33-07 "Guidelines for the improvement and greening of roads," which specifies the requirements for creating strips of green spaces along the roads. Green stripes appropriately designed capture a significant amount of pollution. Green spaces reduce dustiness in the air during the growing season by about $42 \%$, in the absence of leaf cover - by $37 \%$. Trees and shrubs such as elm, linden, maple, lilacs have the greatest capacity for dust retention due to the rough surface of the leaves.

Even small green areas increase the air humidity in the surrounding area by $20-30 \%$. In addition, green spaces reduce wind speed by $50-80 \%$ and climbing plants - by $43 \%$ [10, 11]

The recommended construction of protective strips of green spaces following the regulatory documents of Uzbekistan [12] is $30-40 \mathrm{~m}$.

In Tashkent, most of the streets do not have sufficient technical and pedestrian zones to organize protective landscaping. Therefore, as a rule, streets and highways in the city have only single-row plantings of shrubs and trees, and many streets have no landscaping at all.

It should be noted that the share of city streets and roads with two-sided landscaping is one of the indicators of the environmental sustainability of transport [6]. In Tashkent city, this share, according to the results of studies conducted at the Institute of Irrigation and Agricultural Mechanization Engineers and the Institute for Design, Construction, and Maintenance of Highways, is only $26.6 \%$ [13].

Considering the above, we assume that landscaping of roads should be carried out using lianas. This will create protective green screens in a very limited area, increasing the percentage of streets with double-sided greening and protecting roadside areas from traffic noise and emissions. 
Vertical greening with climbing plants (lianas) is widely used in the world to decorate buildings and create a favorable indoor climate $[14,15,16,17]$. However, lianas are not used anywhere as protective roadside screens, although such proposals have already been made.

At the same time, it is obvious that the shielding of roads with lianas has great prospects: green screens can be formed of any thickness and height, depending on the level of traffic pollution on a given road, and if there is sufficient territory, shielding can be done in several rows.

The purpose of this article is to study the dust-absorbing ability of the leaves of some climbing plants and to assess the possibility of their use for protective landscaping.

\section{Materials and Methods}

\subsection{Research region}

The studies were conducted for the conditions of Tashkent, the capital of the Republic of Uzbekistan

Tashkent lies $457 \mathrm{~m}$ above sea level. The climate is moderately warm; according to the Köppen-Geiger classification, it corresponds to the Csa type. The average annual temperature is $14.1^{\circ} \mathrm{C}$ (with temperature fluctuations from $-6.9^{\circ} \mathrm{C}$ in January to $35.6{ }^{\circ} \mathrm{C}$ in July). In winter, in Tashkent, there is more rainfall than in summer. The average annual precipitation is $623 \mathrm{~mm}$; the relative humidity ranges from 39\% in July to $73 \%$ in January. The average annual wind speed is $1.4 \mathrm{~m} / \mathrm{s}$.

In Tashkent, there is a permanent increased dust content of the air; according to the website https://aqicn.org/city/tashkent/ru/ the air quality is assessed as "unhealthy" and the main pollutant is PM10 and PM2.5 particulate matter. Urban dust is characterized by the presence of soot, formed as a result of combustion processes, and the total dust content in the air in Tashkent exceeds the WHO standards by 2.05 times, the standards of the Republic of Uzbekistan by 1.33 times [18].

\subsection{Determination of dust protection characteristics of leaves}

To establish the dust-collecting ability of the leaves, such climbing plants as fragrant honeysuckle (Lonícera caprifólium) and ivy (Hedera helix) were chosen since in the conditions of Tashkent city both of these species successfully grow on the streets and do not shed their leaves in winter.

Dust collecting capacity was determined by the amount of dust settling on the leaves. For this, the leaves were collected from the bushes of honeysuckle and ivy that grow near highways and in residential areas. For the collection of leaves, 20 bushes of honeysuckle and 20 bushes of ivy, growing in different parts of the city, were selected; at each site, the leaves were collected in summer (June-July) since the dustiness of the air is maximal during the summer period.

From each bush, the leaves were collected three times, 10 pieces each time. The dust holding capacity was checked in two different ways. Half of the collected leaves were placed in a container with $50 \mathrm{ml}$ of water to wash off the dust. Then, water and dust were poured onto a pre-weighed sheet of filter paper. After complete filtration, the filter was dried and reweighed. The difference in weight was used to determine the amount of contamination on the leaves. The specific dust capacity was calculated as the ratio of the dust mass to the leaf area. 
The second part of the collected leaves was weighed immediately; then the dust was washed off, the leaves were dried and weighed again to determine the difference in weight. An analytical balance Radwag AS 220.R2 (made in Poland) with an accuracy of $0.1 \mathrm{mg}$ was used for weighing.

Based on the results of the measurements conducted by the two above methods, the average values of the dust mass were determined.

In laboratory conditions, the maximum dust capacity of leaves was also determined. For this, the collected fresh leaves were placed in an aeration pipe and blown with an air stream of high dust concentration for 5 minutes. After that, the mass of dust collected by the leaves was determined according to the above methods.

\subsection{Determination of the size of the leaf plate and the density of the leaf cover}

The protective properties of green spaces (the ability to trap noise, dust, and exhaust fumes) depend on the size and roughness of the leaves and the foliage density. To determine the size of the leaf plates, 100 pieces of honeysuckle and ivy leaves were randomly selected at various sites in the city and measured using a millimeter grid.

The determination of the foliage density was done using a three-dimensional frame with dimensions $\mathrm{b} \times 1 \times \mathrm{h}=20 \times 30 \times 15 \mathrm{~cm}$. The frame was placed inside the bush, and the leaves in this volume were counted. Then recalculation of the foliage density per $1 \mathrm{~m}^{3}$ was made.

\section{Results and Discussion}

Experiments have shown that the accumulation of dust on the leaves of climbing plants varies depending on the place of growth. Leaves of plants in closed courtyards of residential buildings turned out to be the least dusty. The data obtained as a result of measurements and calculations are presented in Table 1.

Table 1. Average dust capacity of leaves, $\mathrm{mg} / \mathrm{cm}^{2}$

\begin{tabular}{|c|c|c|c|c|}
\hline & $\begin{array}{c}\text { Leaf area, } \\
\mathrm{cm}^{2}\end{array}$ & $\begin{array}{c}\text { In the roadside } \\
\text { zone }(10 \mathrm{~m} \text { from } \\
\text { the edge of the } \\
\text { road) }\end{array}$ & $\begin{array}{c}\text { In a residential } \\
\text { area }(300 \mathrm{~m} \text { from } \\
\text { the road) }\end{array}$ & $\begin{array}{c}\text { With artificial } \\
\text { saturation with } \\
\text { dust }\end{array}$ \\
\hline Ivy & 23.18 & 1.46 & 1.38 & 1.64 \\
\hline Honeysuckle & 14.93 & 0.25 & 0.22 & 0.27 \\
\hline
\end{tabular}

The density of foliage varies greatly on different plants, which can be explained by plant growth conditions (watering, shading). The results for foliage density are presented in Table 2.

Table 2. Density of ivy and honeysuckle foliage

\begin{tabular}{|c|c|c|c|c|}
\hline & \multicolumn{3}{|c|}{ Foliage density, pcs $/ \mathrm{m}^{3}$} & \multirow{2}{*}{$\begin{array}{c}\text { Specific leaf } \\
\text { surface area } \\
\mathrm{cm}^{2} / \mathrm{m}^{3}\end{array}$} \\
\cline { 2 - 4 } & Minimal & Maximal & Average & 233634.2 \\
\hline Ivy & 8753 & 11803 & 10079 & 116827.25 \\
\hline Honeysuckle & 5703 & 11273 & 7825 & 113 \\
\hline
\end{tabular}

As can be seen, ivy leaves' specific dust holding capacity is much higher than that of honeysuckle. This can be explained, apparently, by the rougher surface of the leaves and by the thicker foliage (1.15 times more than that of honeysuckle). As is known from the results of studies by other scientists [19], the property of plants to accumulate dust depends on the 
characteristics of the leaf apparatus and their biological characteristics: leaf pubescence, stickiness, the presence of a wax coating, as well as climatic factors: the amount and nature of precipitation, wind regime, etc. To a large extent, the amount of accumulated dust depends on the distance from the source of pollution and the density of the leaf cover.

The data obtained are consistent with the results of other researchers $[15,19,20,21$, 22]. In particular, Rai $P$, noted that the highest amount of dust is recorded for all plant species in areas close to major highways and in residential areas dense with commercial enterprises. The lowest pollution is in institutional areas with low vehicle density [20].

Studies conducted by Kabanov [19] on the dust holding capacity of birch also show that dust retention by leaves largely depends on the location of plants and their condition. Compared with Kabanov's data, the dust holding capacity of honeysuckle and ivy leaves exceeds the dust holding capacity of birch leaves by 1.89 and 11.79 times, respectively.

When choosing plants for landscaping urban areas, it is very important to know how much oxygen these plants can produce. It is known that gas exchange between the plant and the environment occurs through the leaf stomata. The number of stomata on leaves of Hedera helix L. ivy is 149.2 per $1 \mathrm{~mm}^{2}$ [23], which is 2.2 times higher than that of honeysuckle (about 68 per $1 \mathrm{~mm}^{2}$ according to [24]). Thus, it can be assumed that ivy also has a higher ability to absorb gases in addition to its higher dust holding capacity.

According to [25], $1 \mathrm{~m} 2$ of green leaves produces 5 moles of oxygen per day of 10 hours with regard to the ability to produce oxygen. Half of this oxygen is absorbed by plants during respiration so that the net production of oxygen is 2.5 moles of oxygen per $\mathrm{m}^{2}$ (or $5.6 \mathrm{ml}$ per $1 \mathrm{~cm}^{2}$ ) leaves per day. Considering the average length of daylight hours in Tashkent, 12.1 hours, and data on the area and density of leaves (Tables 1 and 2), it is possible to calculate the amount of oxygen emitted by ivy and honeysuckle leaves. The calculation results are shown in Table 3.

Table 3. The amount of oxygen released by leaves

\begin{tabular}{|c|c|c|}
\hline \multirow{2}{*}{} & \multicolumn{2}{|c|}{ The amount of $\mathrm{O}_{2}$ released } \\
\cline { 2 - 3 } & One sheet, $\mathrm{ml} /$ day & $1 \mathrm{~m}^{3}$ of crown, $\mathrm{l}$ day \\
\hline Ivy & 0.0157 & 1583.1 \\
\hline Honeysuckle & 0.101 & 791.6 \\
\hline
\end{tabular}

It can be seen that from the point of view of oxygen production, the use of ivy is also preferred.

\section{Conclusions}

As a result of the research, it was found that climbing non-deciduous plants (ivy and fragrant honeysuckle) have a high dust-holding ability. In the conditions of dry and dusty air of Tashkent city, these plants can be successfully used for landscaping highways and residential areas for the purpose of dust protection. Given the dense foliage of these plants, it can be assumed that green ivy and honeysuckle screens can provide noise protection as well.

In addition, the planting of ivy and honeysuckle along urban roads will increase the value of such an indicator of the environmental sustainability of road transport as the share of roads with two-way landscaping.

Based on the results obtained, it is possible to recommend creating green screens along city roads from ivy since its ability to both retain dust and reproduce oxygen is much higher than that of honeysuckle. 


\section{Reference}

1. Radkevich M, Shipilova $\mathrm{K}$ et al. assessment of some indices of environmental sustainability of transport in Tashkent Waste Forum 1 pp. 16-31. (2020)

2. Fisher B S, Nakicenovic N at al. In Climate Change 2007: Mitigation. Contribution of Working Group III to the Fourth Assessment Report of the Inter-governmental Panel on Climate Change Issues related to mitigation in the long term context eds Metz B, Davidson O R at al. (Cambridge: Cambridge University Press) chapter 3 pp 171-241. (2007)

3. Dings J. $\mathrm{CO}_{2}$ emissions from transport in the EU27. An analysis of 2008 data submitted to the UNFCCC (Brussels: European Federation for Transport and Environment).(2010)

4. Azarov V, Kutenev V and Stepanov V, On particulate matter emissions from road transport J. of Autom. Eng. 6. (77) pp 55-58. (2012)

5. Resolution of the Cabinet of Ministers of Republic of Uzbekistan "On measures to implement national goals and targets in the field of sustainable development for the period until 2030" (National database of legislation 23.10.2018, No. 09/18/841/2081, 04.06.2019, No. $09 /$ 19/457/3235). [Electronic resource]. Access mode: https://lex.uz/ru/docs/4013358/ (date of access: 10/14/2020)

6. Nathan H S K and Reddy B S, Urban Transport Sustainability Indicators Application of Multi-view Black-box (MVBB) framework (Mumbai Indira Gandhi Institute of Development Research). (2011)

7. Litman $\mathrm{T}$, Well Measured Developing Indicators for Sustainable and Livable Transport Planning (Victoria Transport Policy Institute) (2019).

8. Dobranskyte-Niskota A, Perujo A. and Pregl M, Indicators to Assess Sustainability of Transport Activities Part 1: Review of the Existing Transport Sustainability Indicators Initiatives and Development of an Indicator Set to Assess Transport Sustainability Performance. (Luxembourg: Office for Official Publications of the European Communities) (2007)

9. Chirkova A and Litvinov $\mathrm{P}$, Green spaces as a method of protection against noise and harmful emissions of internal combustion engines in rural areas J. Young Scientist 11 pp. 173-176. (2017)

10. Gorokhov V A, Urban green building. Series: Specialty "Architecture" (Moscow: Stroyizdat). (1991)

11. Susorova I, Azimic P and Stephens B. The effects of climbing vegetation on the local microclimate, thermal performance, and air infiltration of four building facade orientations Build. and Env. 76 pp. 113-124. (2014)

12. Departmental building codes MKN 33-07 Guidelines for the improvement and landscaping of highways (Tashkent: State Joint Stock Company Uzavtoyul) (2007).

13. Shipilova K, Radkevich M, Tsoy V et al. Land use by transport infrastructure in Tashkent city. IOP Conf. Series: Materials Science and Engineering 883012067. (2020)

14. Thottathil V J, Balamuralikrishna C and Ghosh S. Use of green facades in sustainable building environments: quantifying the uptake rates of air pollutants by facades draped with tropical creepers. Proc. of the Int. Sci. Conf. on Sustain. Built Env. (ICSBE-2010) (Kandy) pp. 363-372. (2010).

15. Rai, A., Kulshreshtha, K. and Srivastava, P. K. Leaf surface structure alterations due to particulate pollution in some common plants Environmentalist, 10 pp. 1007-1012. (2009)

16. Perini K, Ottelé $M$ and Raiteri R, Greening the building envelope, façade greening and living wall systems Open J. of Ecol. 1 (1) pp. 1-8. (2011) 
17. Pérez G, Coma J, Martorell I and Cabeza L F, Vertical Greenery Systems (VGS) for energy saving in buildings: A review J. Renew. and Sustain. Ener. Rev. 39. pp. 139165. (2014)

18. Grankina $G$ and Vereshchagina N, Republic of Uzbekistan. Information message on the situation in the country in the field of atmospheric air protection Proc. of Seminar dedicated to promoting the ratification of the Protocols on Heavy Metals and POPs, as well as the Gothenburg Protocol throughout the UNECE (St. Petersburg). (2009).

19. Kabanov A, Kabanova S, Danchenko M and Kochegarov I, study of the peculiarities of the water regime and the dust-holding capacity of Betula pendula Roth crops. in North Kazakhstan Vestnik RUDN. Series: Agronomy and animal husbandry 15 (4) pp. 325-334. (2020)

20. Rai P, Biodiversity of roadside plants and their response to air pollution in an IndoBurma hotspot region: implications for urban ecosystem restoration. J. of Asia-Pacific Biodiversity 9 pp. 47-55. (2016)

21. Sergeychik S, Gas absorption capacity of plants and the accumulation of industrial pollution elements in them. Optimization of the environment by means of landscaping (Minsk: Science and technology) pp. 68-75. (1985).

22. Danchenko M. System of silvicultural measures to increase the recreational capacity and sustainability of urban forests J. Bulletin of Tomsk State University 347 pp. 156-158. (2011)

23. Panesh O Kraynyukova E. Structure of the leaf stomatic apparatus of relic plants (by using an example of relic species of the city of Maikop) Bulletin of Altai State University 4 (231) pp. 129-132. (2018)

24. Sagynbaeva G. The structure of the leaf organs of some types of honeysuckle Izvestia VUZOV 2 pp. 45-54. (2015)

25. Streever W J. Kooragang Wetland Rehabilitation Project: opportunities and constraints in an urban wetland rehabilitation project Urban Ecosystems 2 pp. 205218. (1998) 